\title{
Cerebral arteriovenous oxygen difference: a predictor of cerebral infarction and outcome in patients with severe head injury
}

Peter D. Le Roux, M.B., Ch.B., M.D., David W. Newell, M.D., Arthur M. Lam, M.D., F.R.C.P.C., M. Sean Grady, M.D., and H. Richard Winn, M.D.

Departments of Neurosurgery and Anesthesiology, Harborview Medical Center, University of Washington, Seattle, Washington

Jugular bulb oxygen monitoring can be used to estimate the adequacy of cerebral blood flow to support cerebral metabolism after severe head injury. In the present study, the authors studied the cerebral arteriovenous oxygen difference $\left(\mathrm{AVDO}_{2}\right)$ before and after treatment in 32 head-injured patients (Glasgow Coma Scale scores $3 / 48$ ) to examine the relationships among $\mathrm{AVDO}_{2}$ and cerebral perfusion pressure (CPP), delayed cerebral infarction, and outcome. Fifteen patients (Group A) underwent craniotomy for hematoma evacuation and 17 (Group B) received mannitol for sustained intracranial hypertension (intracranial pressure $>20 \mathrm{~mm} \mathrm{Hg},>10$ minutes). Radiographic evidence of delayed cerebral infarction was observed in 14 patients. Overall, 17 patients died or were severely disabled. Cerebral $\mathrm{AVDO}_{2}$ was elevated before craniotomy or mannitol administration; the mean $\mathrm{AVDO}_{2}$ for all patients before treatment was $8.6 \pm 1.8 \mathrm{vol} \%$. Following craniotomy or mannitol administration, the $\mathrm{AVDO}_{2}$ decreased in 27 patients and increased in five patients (mean $\mathrm{AVDO}_{2} 6.2 \pm 2.1 \mathrm{vol} \%$ in all patients; $6 \pm 1.9$ vol\% in Group A; and $6.4 \pm 2.4$ vol\% in Group B). The mean CPP was $75 \pm 9.8 \mathrm{~mm} \mathrm{Hg}$ and no relationship with $\mathrm{AVDO}_{2}$ was demonstrated. Before treatment, the $\mathrm{AVDO}_{2}$ was not associated with delayed cerebral infarction or outcome. By contrast, a limited improvement in elevated $\mathrm{AVDO}_{2}$ after craniotomy or mannitol administration was significantly associated with delayed cerebral infarction (Group A: $\mathrm{p}<0.001$; Group B: $\mathrm{p}<0.01$ ). Similarly, a limited improvement in elevated $\mathrm{AVDO}_{2}$ after treatment was significantly associated with an unfavorable outcome (Group A: p < 0.01; Group B: $\mathrm{p}<$ 0.001 ). In conclusion, these findings strongly indicate that, despite adequate cerebral perfusion, limited improvement in elevated cerebral $\mathrm{AVDO}_{2}$ after treatment consisting of either craniotomy or mannitol administration may be used to help predict delayed cerebral infarction and poor outcome after traumatic brain injury.

Key Words * traumatic brain injury * arteriovenous oxygen difference * intracranial pressure * cerebral ischemia * outcome

Neuropathological studies demonstrate that cerebral ischemia is frequently found in patients who die after head injury.[19] In addition, cerebral infarction is observed on sequential computerized tomography (CT) scans in disabled survivors.[31] Intracranial hypertension is also a common occurrence after severe head injury and may contribute to cerebral ischemia by reducing cerebral perfusion pressure (CPP); 
however, the relationship among intracranial pressure (ICP), CPP, and the development of cerebral ischemia is not consistent.[24,33,50] This discrepancy may result, in part, from other factors not reflected in either ICP or CPP, such as disturbed autoregulation,[2,14,34] traumatic vasospasm,[29] or neurochemical changes such as elevated excitatory amino acids,[1] which may adversely influence cerebral blood flow $(\mathrm{CBF})$ or tissue oxygenation and contribute to infarction.

Several techniques have been developed to determine the adequacy of CBF after severe head injury. Although it does not measure absolute $\mathrm{CBF}$ values, jugular bulb oxygen monitoring provides an estimate of the adequacy of CBF to support cerebral metabolism by measuring the balance between oxygen delivery and consumption. Previous investigators have demonstrated that in the absence of infarction or necrosis, the cerebral arteriovenous oxygen difference $\left(\mathrm{AVDO}_{2}\right)$ and $\mathrm{CBF}$ are inversely related.[37,43] The present study of severely head injured patients was undertaken to examine: 1) the $\mathrm{AVDO}_{2}$ response to craniotomy or mannitol administration; 2) the relationships among $\mathrm{AVDO}_{2}, \mathrm{ICP}$, and CPP; and 3) the associations between $\mathrm{AVDO}_{2}$ and delayed cerebral infarction and outcome. Our results demonstrate that there was a poor relationship between $\mathrm{CPP}$ and $\mathrm{AVDO}_{2}$. However, limited improvement in an elevated $\mathrm{AVDO}_{2}$ following craniotomy for traumatic mass lesions or mannitol administration for intracranial hypertension was significantly associated with delayed cerebral infarction and poor outcome. By contrast, a large improvement in $\mathrm{AVDO}_{2}$ was associated with favorable outcome and no evidence of delayed cerebral infarction.

\section{CLINICAL MATERIAL AND METHODS}

\section{Patient Population}

During a 12-month period, 32 patients with severe traumatic brain injury (postresuscitation Glasgow Coma Scale[GCS][51] scores of $3 / 4$ 8) admitted to our institution within 8 hours of injury were prospectively evaluated. There were 21 males and 11 females in the group, ranging in age from 14 to 79 years (median 34.5 years). The patients fulfilled the following criteria: 1) isolated nonpenetrating head injury; 2) normal blood pressure; 3) normothermia; 4) hematocrit above 30\%; and 5) survival more than 24 hours after admission. Two groups were identified: Group A (15 patients) underwent craniotomy for evacuation of a traumatic mass lesion and Group B (17 patients) demonstrated no mass lesion on a CT scan but received a mannitol infusion for sustained intracranial hypertension (ICP > $20 \mathrm{~mm} \mathrm{Hg},>10$ minutes) despite adequate sedation and ventilation.

\section{Case Management}

All patients were managed according to a standard protocol that emphasized prompt evacuation of intracranial mass lesions and prevention of secondary cerebral insults. Patients suffering severe head injury were initially evaluated and aggressively resuscitated, including intubation and mechanical ventilation, by paramedics in the field. On admission to the emergency department, the patients were hemodynamically stabilized and, after initial evaluation, all underwent cranial CT scanning. Patients with surgical mass lesions were taken directly to the operating room for hematoma evacuation. All patients were admitted to the neurosurgical intensive care unit and their cases were managed according to a standard protocol designed to prevent secondary insults. This protocol included: 1) intubation and mechanical ventilation to maintain $\mathrm{PaO}_{2}$ at above $100 \mathrm{~mm} \mathrm{Hg}$ and $\mathrm{PaCO}_{2}$ at 30 to $35 \mathrm{~mm} \mathrm{Hg}$; 2) volume replacement with albumin and crystalloid boluses to maintain systolic blood pressure at more than 100 
$\mathrm{mm} \mathrm{Hg}$ and central venous pressure between $5 \mathrm{~cm}$ and $10 \mathrm{~cm} \mathrm{H}_{2} \mathrm{O} ; 3$ ) maintenance of normal serum glucose and electrolyte levels and a hematocrit of between $30 \%$ and $40 \%$; and 4) treatment of increased ICP (> $20 \mathrm{~mm} \mathrm{Hg}$ ) in the following sequence: sedation (morphine sulfate), muscle paralysis (pancuronium therapy), head elevation (10-30š), and moderate hyperventilation $\left(\mathrm{PaCO}_{2}\right.$ maintained at 25-30 $\mathrm{mm} \mathrm{Hg}$ ). If a patient's ICP remained elevated (> $20 \mathrm{~mm} \mathrm{Hg},>10$ minutes) despite these measures, an intravenous bolus of $20 \%$ mannitol was administered over 10 to 15 minutes $(0.5-1 \mathrm{~g} / \mathrm{kg})$.

\section{Physiological Measurements}

The following physiological parameters were continuously monitored: arterial blood pressure through a radial arterial catheter; arterial oxygen saturation $\left(\mathrm{SaO}_{2}\right)$ by pulse oximetry; end-tidal $\mathrm{CO}_{2}$ using a capnometer installed through the endotracheal tube; temperature measured through an esophageal temperature probe in the operating room or by tympanic thermometer in the intensive care unit; and ICP through a fiberoptic parenchymal intracranial pressure monitor (Camino Laboratories, San Diego, CA). The level of cerebral perfusion was calculated as the difference between the mean arterial blood pressure $(\mathrm{MABP})$ and ICP $(\mathrm{CPP}=\mathrm{MABP}$ - ICP). All parameters were recorded in a computerized database and were correlated with the $\mathrm{AVDO}_{2}$ measurements.

\section{Determination of Cerebral Arteriovenous Oxygen Difference}

To measure jugular venous oxygen saturation $\left(\mathrm{SjVO}_{2}\right)$, a 5.5-in-long 16-gauge catheter was inserted percutaneously into the internal jugular vein.[22] The catheter tip, confirmed by x-ray film, was positioned in the jugular bulb. The catheter was placed on the side of the mass lesion to be evacuated or, in Group B patients, in the dominant jugular vein based on a CT assessment of the jugular foramen.[12] The ICP monitor was placed ipsilateral to the jugular catheter. Arterial (radial) and retrograde jugular venous samples were obtained simultaneously: 1) at skin incision and skin closure in patients undergoing craniotomy and 2) before and 30 minutes after completing intravenous mannitol administration. The samples were used to determine $\mathrm{pH}, \mathrm{PaO}_{2}, \mathrm{PaCO}_{2}, \mathrm{O}_{2}$ saturation, and hemoglobin $(\mathrm{Hb})$ (Corning 170 blood gas analyzer; Corning Medical Instruments, Medfield, MA). The $\mathrm{AVDO}_{2}$ was calculated according to the following formula: $\mathrm{AVDO}_{2}=\mathrm{Hb} \mathrm{X} 1.34\left(\mathrm{SaO}_{2}-\mathrm{SvO}_{2}\right)+0.003\left(\mathrm{PaO}_{2}-\mathrm{PvO}_{2}\right)$.

\section{Diagnosis of Delayed Cerebral Infarction}

Cranial CT scans (model GE 9800; General Electric Medical Systems, Milwaukee, WI) were obtained in all patients at admission, shortly after surgery or mannitol infusion (1-2 hours), on a daily basis for 3 days, and 1 week after admission. A low attenuation region conforming to a vascular territory identified on CT scanning was regarded as radiographic evidence of delayed infarction if an area of hypoperfusion in the same region was identified on a nuclear medicine single-photon emission CT scan obtained using 99mTc-hexamethylpropyleneamine oxime (Fig. 1). Additional criteria for distinguishing an infarcted area from edema was the restriction of the hypodense area to a vascular territory, distinct margins, and persistence beyond the acute injury phase. Isolated low attenuation abnormalities in the posterior cerebral artery distribution were regarded as evidence of herniation and not of infarction. 

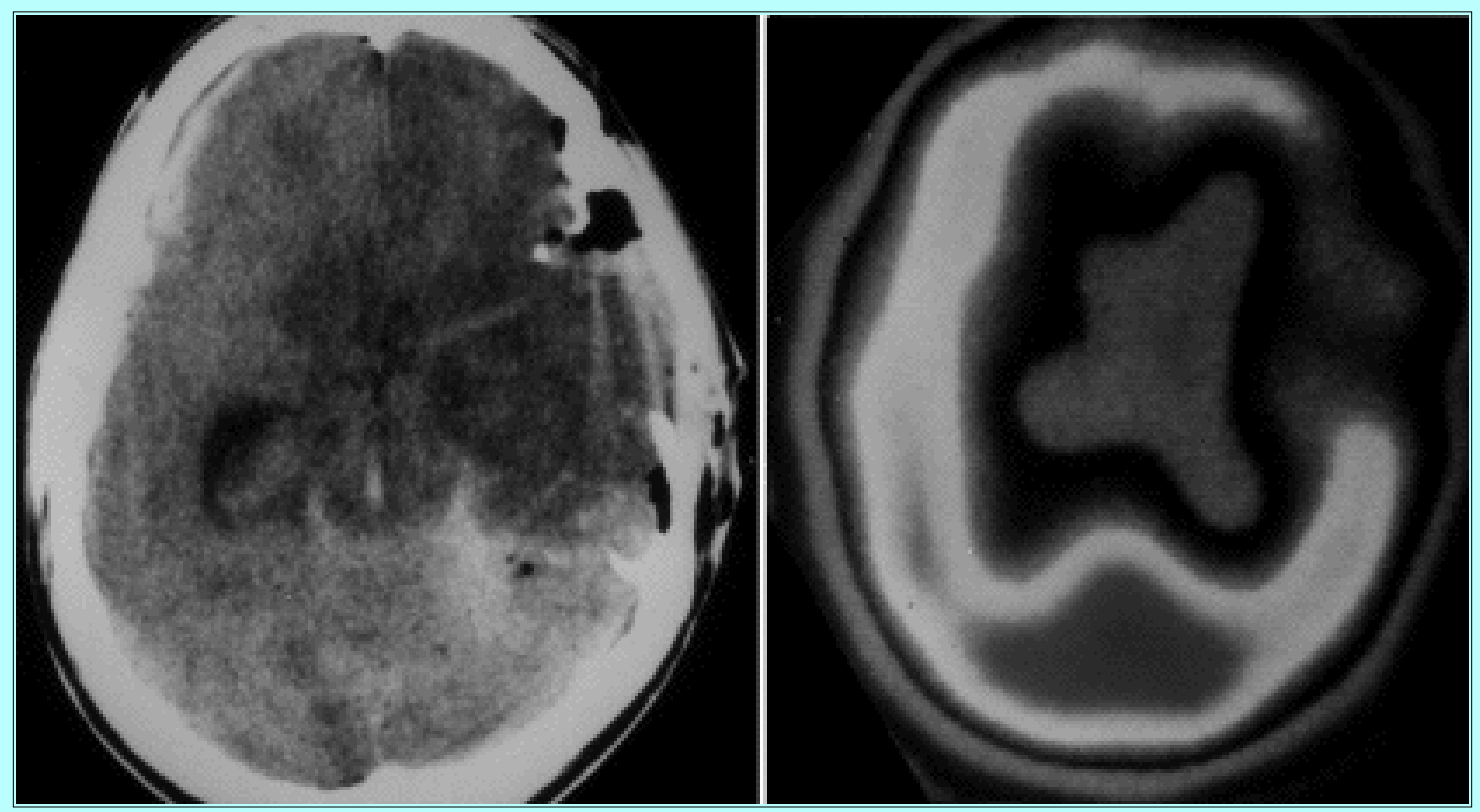

Fig. 1. Computerized tomography (left) and single-photon emission CT (right) scans illustrating radiographic changes of delayed cerebral infarction. There was histological confirmation of this radiological diagnosis in four patients who underwent autopsy.

\section{Patient Outcome}

Outcome was assessed 6 months after head injury, by means of a clinic visit or telephone interview, according to the Glasgow Outcome Scale[23] (GOS). Patients with a GOS score of "good" or "moderately disabled" are independent for all their needs and participate in a normal social life; for statistical comparison, these patients were classified as having a favorable outcome. Unfavorable outcome was assigned to those patients who died or were not capable of an independent existence.

\section{Statistical Analysis}

Data are expressed as the mean \pm standard deviation or, in situations in which samples depart substantially from normal distributions, they are summarized as the median. A two-sample significance of data that departed from a normal distribution was tested using the Mann-Whitney U test. Student's t-test was used to assess differences between groups when the samples were normally distributed. When appropriate, Pearson's chi-square test was used to test for sample differences on categorical variables. Fisher's exact test was substituted when one or more cells had expected frequencies less than five. Simple regression analysis or Pearson's correlation was used to relate continuous variables to one another. In the case of multiple associations, Bonferronian inequality was used. Statistical significance is assumed for comparisons in which probability is less than 0.01. All statistical analyses were performed using a commercially available software package (StatView II, 1987; Abacus Concepts, Berkeley, CA). 


\begin{tabular}{|c|c|c|}
\hline \multirow[b]{2}{*}{ Characteristic } & \multicolumn{2}{|c|}{ No. of Patierts } \\
\hline & $\begin{array}{c}\text { Group A } \\
\text { [craniotomy] } \\
\text { (15 pab ents) }\end{array}$ & $\begin{array}{l}\text { Group B } \\
\text { (m anritol) } \\
\text { (17 pabients] }\end{array}$ \\
\hline $\begin{array}{l}\text { median age in yrs (range) } \\
\text { sex (male female) } \\
\text { admission GCS score }\end{array}$ & $\begin{array}{c}50(23-79) \\
9: 6\end{array}$ & $\begin{array}{c}31(14-79) \\
12: 5\end{array}$ \\
\hline $\begin{array}{l}3-5 \\
6-8\end{array}$ & $\begin{array}{r}10 \\
5\end{array}$ & $\begin{array}{r}13 \\
4\end{array}$ \\
\hline \multicolumn{3}{|l|}{ type of injury } \\
\hline diffuse head injury & 0 & 12 \\
\hline single fmultiple contusion(s) & 0 & 3 \\
\hline in traventricular hemorhage & 0 & 2 \\
\hline subdural hematoma & 7 & 0 \\
\hline in traceretral hematoma & 6 & 0 \\
\hline cerebral swelling & 2 & 0 \\
\hline mean ICP posttreatment (mm Hg) & $13 \pm 3.2$ & $22 \pm 8.3$ \\
\hline mean CPP posttreatment ( $\mathrm{mm}$ Hg) & $80 \pm 7.1$ & $71 \pm 9.9$ \\
\hline \multicolumn{3}{|l|}{ outcome (GOs score at 6 mos) } \\
\hline goodimoderately disabled & 8 & 7 \\
\hline Severely disabled hegetati ue & 1 & 3 \\
\hline dead & 6 & 7 \\
\hline
\end{tabular}

\section{RESULTS}

\section{Patient Characteristics}

The clinical characteristics of the patients are summarized in Table 1 . The majority of patients (25) were injured in motor vehicle accidents; four patients were injured in a fall, and three suffered blunt trauma. Fifteen patients underwent craniotomy for mass lesions (Group A), whereas 17 patients received intravenous administration of mannitol for elevated ICP (Group B). Overall, the mean ICP following craniotomy or mannitol administration was $17.8 \pm 7.8 \mathrm{~mm} \mathrm{Hg}$ (Table 1). The CPP was greater than 70 $\mathrm{mm} \mathrm{Hg}$ in 27 patients, between 60 and $70 \mathrm{~mm} \mathrm{Hg}$ in four Group B patients, and less than $60 \mathrm{~mm} \mathrm{Hg}$ in one Group B patient. The mean CPP was greater in Group A than Group B patients; overall, the mean posttreatment CPP was $75 \pm 9.8 \mathrm{~mm} \mathrm{Hg}$ (Table 1). 

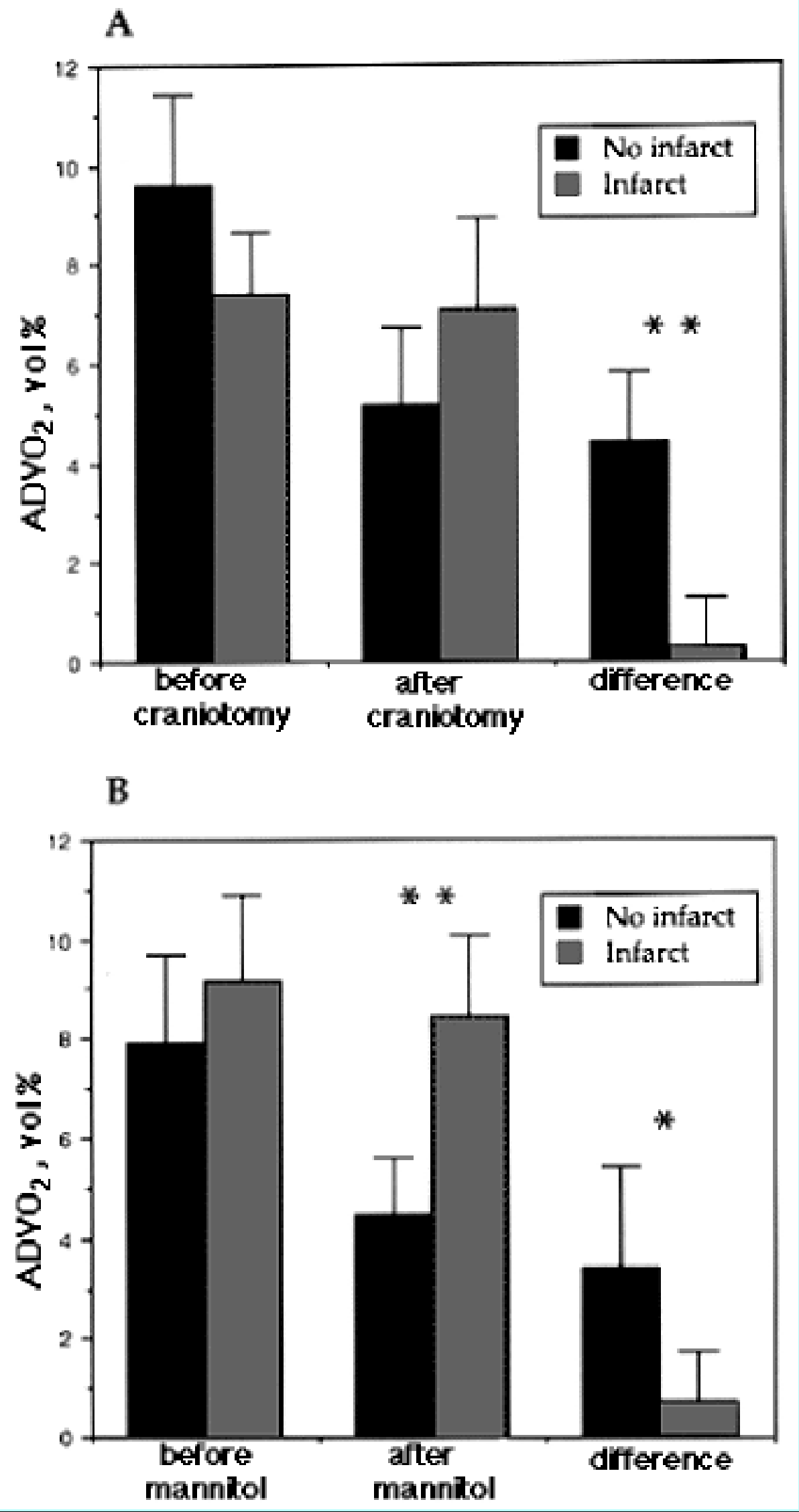

Fig. 2. Histograms showing the relationship between cerebral $\mathrm{AVDO}_{2}$ and delayed cerebral infarction. Values represent the mean $\mathrm{AVDO}_{2}$ ( \pm standard deviation) in patients undergoing craniotomy for traumatic mass lesions (A) or mannitol administration for intracranial 
hypertension (B). Whereas $\mathrm{AVDO}_{2}$ prior to craniotomy (A) or mannitol administration (B) was not associated with radiographic evidence of cerebral infarction, limited improvement in elevated $\mathrm{AVDO}_{2}$ after treatment was significantly associated with delayed cerebral infarction. ${ }^{*} \mathrm{p}<0.01 ; * \mathrm{*}<0.001$.

\section{Cerebral Arteriovenous Oxygen Difference}

Cerebral $\mathrm{AVDO}_{2}$ was elevated before craniotomy or mannitol administration; the mean $\mathrm{AVDO}_{2}$ for all patients before treatment was $8.6 \pm 1.8 \mathrm{vol} \%$. Following craniotomy or mannitol administration, the $\mathrm{AVDO}_{2}$ decreased in 27 patients and increased in five; overall, the mean posttreatment $\mathrm{AVDO}_{2}$ was 6.2 \pm 2.1 vol\% (Group A, $6 \pm 1.9$ vol\%; Group B, $6.4 \pm 2.4$ vol\%). The calculated $\mathrm{AVDO}_{2}$ demonstrated a significant inverse relationship to $\mathrm{SjVO}_{2}$ both before $(\mathrm{r}=-0.7, \mathrm{p}=0.001)$ and after treatment $(\mathrm{r}=-0.8, \mathrm{p}$ $<0.001)$. Group B results represent only values obtained before and after the first mannitol treatment. When all values obtained for a given patient receiving multiple mannitol infusions were averaged similar findings were observed. There were no complications related to the use of jugular bulb catheters.

\section{Delayed Cerebral Infarction and Arteriovenous Oxygen Difference}

Radiographic evidence of delayed cerebral infarction was identified in six Group A patients and eight Group B patients. The relationship between $\mathrm{AVDO}_{2}$ and delayed cerebral infarction is illustrated in Fig. 2. The mean $\mathrm{AVDO}_{2}$ before craniotomy or mannitol infusion was similar in patients who subsequently did or did not develop radiographic evidence of delayed cerebral infarction. By contrast, after treatment both an elevated $\mathrm{AVDO}_{2}(\mathrm{p}<0.001)$ and a limited improvement (reduction) in an elevated $\mathrm{AVDO}_{2}(\mathrm{p}<$ 0.001 ) were significantly associated with the development of delayed cerebral infarction. All five patients who demonstrated an increase in $\mathrm{AVDO}_{2}$ and all six patients who demonstrated a decrease in $\mathrm{AVDO}_{2}$ that was less than $1 \mathrm{vol} \%$ following treatment developed delayed cerebral infarction. By contrast, among the 22 patients in whom the $\mathrm{AVDO}_{2}$ decreased greater than $1 \mathrm{vol} \%$, delayed cerebral infarction was observed in only four (19\%). 


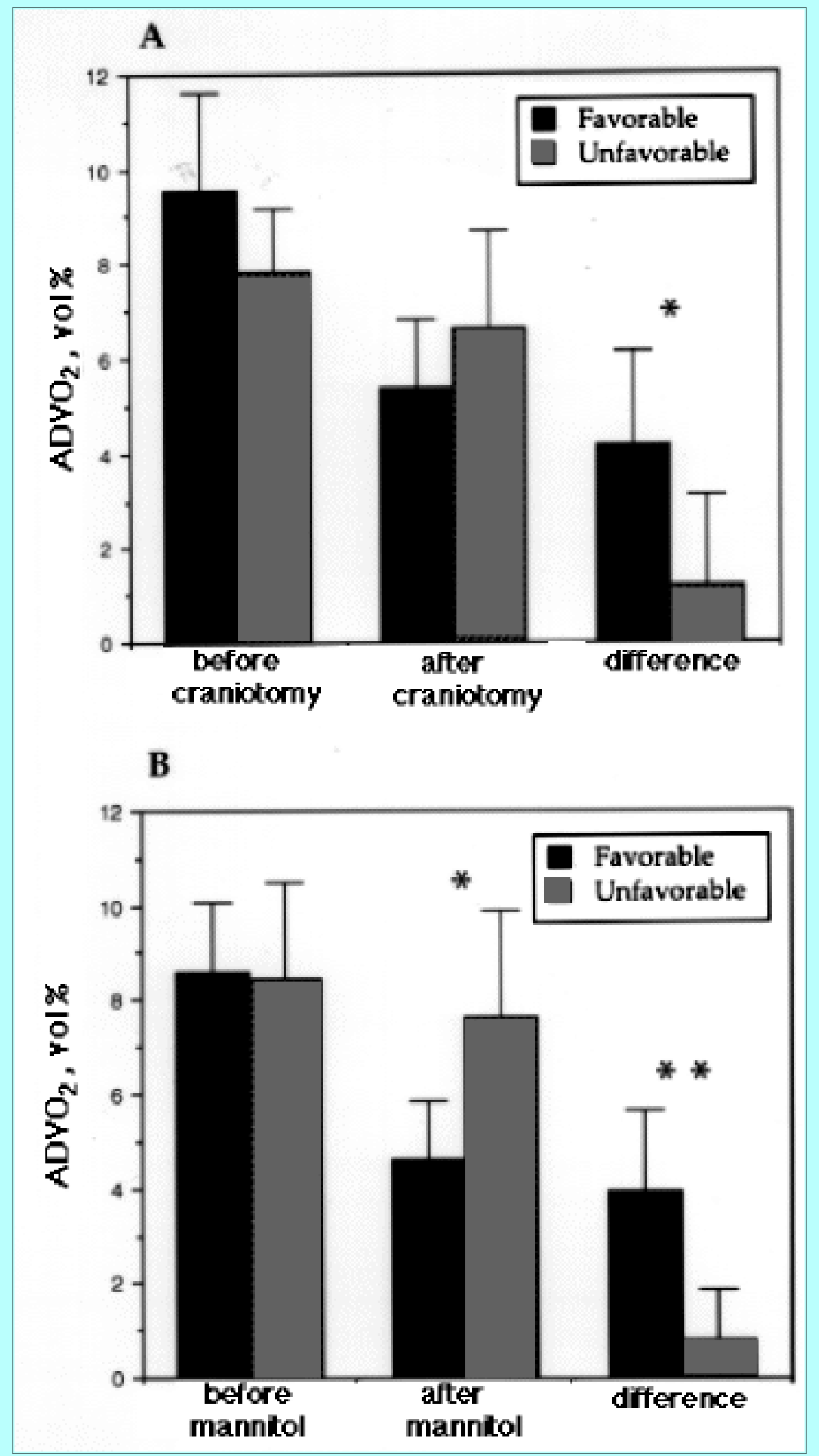

Fig. 3. Histograms showing the relationship between cerebral $\mathrm{AVDO}_{2}$ and $\mathrm{GOS}$ score at 6 months posttreatment. Values represent the mean $\mathrm{AVDO}_{2}$ ( \pm standard deviation) in patients undergoing craniotomy for traumatic mass lesions (A) or mannitol administration for 
intracranial hypertension (B). Before treatment the $\mathrm{AVDO}_{2}$ was not associated with outcome. By contrast, limited improvement in elevated $\mathrm{AVDO}_{2}$ after treatment was significantly associated with an unfavorable outcome. $* \mathrm{p}<0.01,{ }^{*} \mathrm{p}<0.001$.

\section{Outcome and $\mathrm{AVDO}$}

Outcome was assessed at 6 months: 13 patients had died, four remained in a persistent vegetative state or were severely disabled, and 15 had made a favorable recovery (Table 1). Delayed cerebral infarction was identified in $85 \%$ of patients who experienced an unfavorable outcome, whereas only $13 \%$ of patients who experienced a favorable outcome demonstrated radiographic evidence for delayed cerebral infarction $(\mathrm{p}<0.01)$. The relationship between $\mathrm{AVDO}_{2}$ and outcome is summarized in Fig. 3 . Whereas the $\mathrm{AVDO}_{2}$ before treatment was similar, an elevated posttreatment $\mathrm{AVDO}_{2}(\mathrm{p}=0.002)$ and a limited improvement in an elevated $\mathrm{AVDO}_{2}$ after treatment $(\mathrm{p}<0.001)$ were significantly associated with an unfavorable outcome. Unfavorable outcomes were observed in all five patients who demonstrated an increase in $\mathrm{AVDO}_{2}$ and in five (83\%) of the six patients in whom the $\mathrm{AVDO}_{2}$ decreased less than 1 vol\%. When posttreatment $\mathrm{AVDO}_{2}$ decreased more than 1 vol\% (21 patients), seven patients (33\%) experienced an unfavorable outcome.

\section{Other Variables}

An important point in the interpretation of our results is the relationship between $\mathrm{AVDO}_{2}$ and variables such as age, admission GCS score, ICP, and CPP. Before treatment no relationship was observed. After treatment, a moderate relationship between $\mathrm{AVDO}_{2}$ and age $(\mathrm{r}=0.4, \mathrm{p}=0.01)$ and between $\mathrm{AVDO}_{2}$ and ICP $(r=0.5, p=0.003)$, particularly in mannitol-treated patients, was observed. No relationship between posttreatment $\mathrm{AVDO}_{2}$ and admission GCS score or posttreatment CPP was observed.

The association between delayed infarction or outcome and age, admission GCS score, ICP, or CPP was examined using bivariate analysis; the results are listed in Tables 2 and 3. Advanced age was significantly associated with delayed cerebral infarction $(\mathrm{p}=0.002)$ and older patients undergoing craniotomy were more likely to experience an unfavorable outcome $(\mathrm{p}=0.004)$. The admission GCS score did not predict delayed cerebral infarction, but a low admission GCS score was associated with unfavorable outcome $(\mathrm{p}=0.006)$. In patients treated with mannitol there was a significant association between elevated posttreatment, but not pretreatment, ICP and delayed cerebral infarction $(\mathrm{p}=0.004)$. An association between CPP and delayed infarction or outcome was not observed. 
TABLE 2

FACTORS ASSOC ATED WITH RADOGRAPHIC EVIDENCE FOR DELAVED CEREBRAL INFARCTION IN 32 PATIENTS WITH SEVERE HEAD IN.URV *

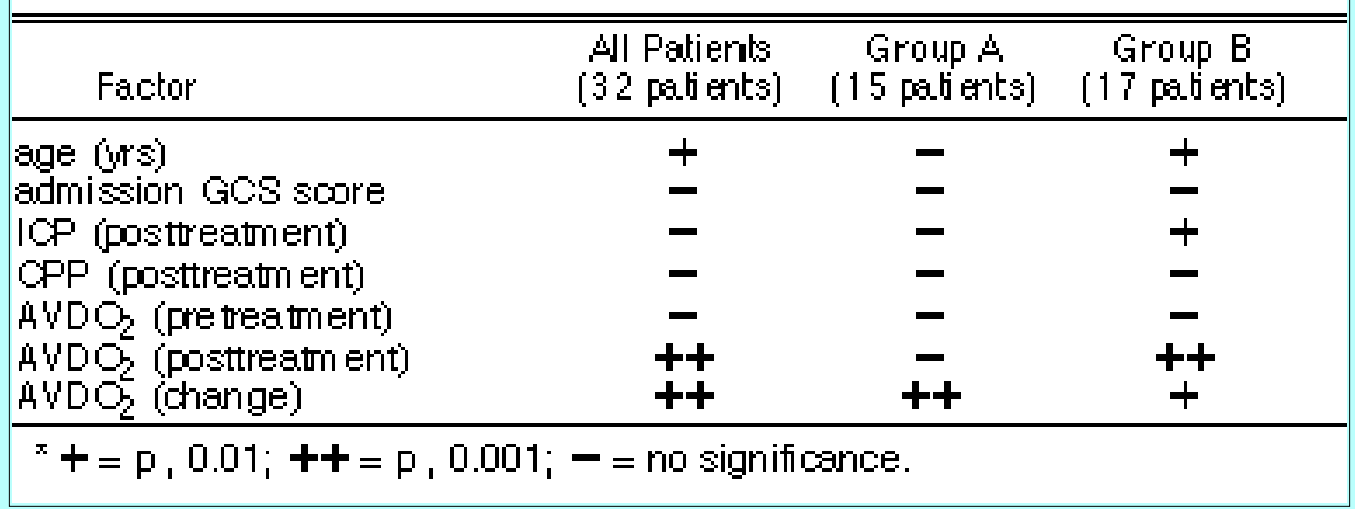

\section{DISCUSSION}

In the present report we describe our experience using jugular bulb monitoring in 32 severely head injured patients. The results demonstrate that $\mathrm{AVDO}_{2}$ is elevated in patients suffering traumatic mass lesions or intracranial hypertension. When measured before craniotomy or mannitol administration, the $\mathrm{AVDO}_{2}$ was not predictive of delayed cerebral infarction or outcome. By contrast, limited improvement in an elevated $\mathrm{AVDO}_{2}$ after either craniotomy or mannitol administration was significantly associated with both delayed cerebral infarction and unfavorable outcome. In addition, a relationship between CPP and $\mathrm{AVDO}_{2}$ was not observed. These findings emphasize the complex pathophysiology leading to delayed cerebral infarction and the need for repeated or continuous observations in patients suffering severe traumatic brain injury.

\begin{tabular}{|c|c|c|c|}
\hline FACTORS ASSOC KTE & $\begin{array}{l}\text { TABLE } 3 \\
\text { JTCOME } 6 \text { MOR } \\
\text { TH SEYERE HE }\end{array}$ & $\begin{array}{l}\text { THS AFTER TRE } \\
\text { AD INWJRY }\end{array}$ & ATMENT IN 32 \\
\hline Factor & $\begin{array}{c}\text { Al Patients } \\
\text { (32 patients) }\end{array}$ & $\begin{array}{c}\text { Group } A \\
\text { (15 patients) }\end{array}$ & $\begin{array}{c}\text { Group B } \\
\text { (17 pab ents) }\end{array}$ \\
\hline age (urs) & - & + & - \\
\hline admission GCS soore & + & - & - \\
\hline IOP (posttreatment) & - & - & - \\
\hline CPP (posttreatm ent) & - & - & - \\
\hline $\mathrm{AVDO}_{2}$ (pre treatment) & - & - & - \\
\hline AVDO (postreatm ent) & + & - & + \\
\hline AVDO- (change) & ++ & + & ++ \\
\hline
\end{tabular}

\section{Methodological Considerations}

There are several important points to bear in mind when interpreting jugular bulb oxygen monitoring results. First, focusing on blood samples from one jugular bulb may lead one to overlook ischemia or infarction in the other hemisphere because differences in oxygen saturation between the two hemispheres can occur. These differences, however, are of potential clinical significance in individuals with unilateral lesions.[15,16,47,48] The likelihood of missing contralateral abnormalities was reduced in this study by placing the catheter ipsilateral to mass lesions because experimental and clinical studies demonstrate that ischemia is generally identified adjacent to traumatic lesions.[25,30,45] In Group B patients (who had no mass lesion) the catheter was placed on the dominant side of jugular flow, usually the right side, by 
evaluating the size of the jugular foramen on CT scanning.[12] The ICP monitor was placed ipsilateral to the jugular catheter. Second, $\mathrm{AVDO}_{2}$ samples may lead one to miss regional ischemia. We cannot rule out this possibility but we believe that it is unlikely because radiographic evidence of infarction, which always correlated with a defined vascular territory, was only observed in patients in our study whose posttreatment $\mathrm{AVDO}_{2}$ was greater than $6 \mathrm{vol} \%$. By contrast, when posttreatment $\mathrm{AVDO}_{2}$ was less than 6 vol\%, no evidence for cerebral infarction was observed. Third, extracerebral contamination may be associated with sample withdrawal, particularly when CBF is low. Dye injection studies, however, demonstrate that jugular bulb samples contain insignificant amounts of extracerebral blood, provided the catheter is within the jugular bulb.[47] We were careful, therefore, to obtain radiographic confirmation of the catheter position in all patients. Finally, there is the question as to whether venous obstruction in the neck can elevate ICP. We think this problem is unlikely because we did not observe an ICP increase during catheter insertion. Studies by Goetting and Preston[17] have similarly demonstrated no evidence of jugular vein obstruction that is sufficient to elevate ICP in the catheterized vessel. Bearing these caveats in mind, when used carefully, jugular bulb oxygen saturation monitoring may provide a reliable estimate of cerebral oxygenation.

\section{Arteriovenous Oxygen Difference and Cerebral Ischemia}

Our results demonstrate that before treatment an elevated $\mathrm{AVDO}_{2}$ cannot be used to predict delayed cerebral infarction. By contrast, limited improvement in an elevated $\mathrm{AVDO}_{2}$ after treatment, despite adequate $\mathrm{CPP}$, is significantly associated with delayed cerebral infarction. In studies comparing $\mathrm{AVDO}_{2}$ and $\mathrm{CBF}$, the highest $\mathrm{AVDO}_{2}$ values correlate with reduced $\mathrm{CBF}$, whereas low $\mathrm{AVDO}_{2}$ values are observed in hyperemic patients.[4,36-38,43] Similarly, therapeutic manipulations that decrease or increase $\mathrm{CBF}$ are associated with an increase and decrease in $\mathrm{AVDO}_{2}$, respectively.[35,43] The initial pretreatment $\mathrm{AVDO}_{2}$ value, therefore, indicates that the brain is compensating for reduced flow by extracting more oxygen. Where sufficient aerobic reserve existed, the $\mathrm{AVDO}_{2}$ improved after treatment, but in those patients with an exhausted reserve, no improvement in $\mathrm{AVDO}_{2}$ was observed and delayed infarction occurred. The extent of aerobic reserve may partly explain the association of advanced age, $\mathrm{AVDO}_{2}$, and infarction because older patients are more likely to demonstrate atherosclerosis and vascular disease and thus have limited compensatory reserve. The lack of $\mathrm{AVDO}_{2}$ improvement, however, represents a preinfarction state because the posttreatment $\mathrm{AVDO}_{2}$ remained elevated. By contrast, cerebral infarction is associated with a significant reduction in $\mathrm{AVDO}_{2}$ because the cerebral metabolic rate of oxygen decreases when tissue dies.[37,43] In patients with cerebral infarction, knowledge of cerebral lactate may be useful;[42] however, the compensated but hypoperfused state is important to recognize because the deleterious effects of ischemia and hypoxia may still be ameliorated.

\section{Cerebral Perfusion Pressure and Cerebral Infarction}

We did not observe a correlation between $\mathrm{AVDO}_{2}$ and CPP, whereas a relationship between ICP and $\mathrm{AVDO}_{2}$ was observed. Experimental studies using magnetic resonance spectroscopy have demonstrated that ICP and $\mathrm{AVDO}_{2}$ correlate with brain energy failure, as identified by changes in phosphocreatine. By contrast, brain energy failure occurs over a wide range of CPPs.[49,50] Similarly, clinical studies have demonstrated that baseline CBF values may not correlate with CPP or ICP.[30] Other studies, however, have demonstrated a significant linear correlation among $\mathrm{CPP}$ (but not ICP) and $\mathrm{SjVO}_{2}$ and $\mathrm{AVDO}_{2}$, 
provided the CPP is less than $70 \mathrm{~mm} \mathrm{Hg.[7,8]} \mathrm{The} \mathrm{majority} \mathrm{of} \mathrm{patients} \mathrm{in} \mathrm{our} \mathrm{series,} \mathrm{however,}$ demonstrated CPPs greater than $70 \mathrm{~mm} \mathrm{Hg}$, which in part may explain the poor correlation between $\mathrm{AVDO}_{2}$ and CPP. It is also conceivable that increased ICP may reflect the irreversible end result of biochemical and cellular events, rather than act as the cause of neuron damage, and thus may demonstrate a relationship with $\mathrm{AVDO}_{2}$.

An important finding in this series was the radiographic evidence of delayed cerebral infarction despite an adequate CPP. This finding is consistent with experimental studies in which an ischemic zone has been shown adjacent to subdural hematomas in rats with an adequate CPP.[32] Therapy based on CPP maintenance[44] or determination of an ideal CPP by calculation of a transcranial Doppler pulsatility index and $\mathrm{SjVO}_{2}$ for individual patients[7,8] have been demonstrated to be feasible management strategies for head-injured patients. We believe that an adequate CPP is important in head injury management. However, our results indicate that an adequate CPP alone is insufficient to prevent cerebral infarction in all patients. The progression to infarction despite adequate CPP may be explained by altered autoregulation, direct toxicity from blood, or neurochemical alterations. For example, experimental models of traumatic hematoma[6] or diffuse axonal injury[13] and clinical studies[1] demonstrate that levels of excitatory amino acids, such as glutamate, which in high concentrations appear integral to the pathophysiological mechanism of neuron injury and death in cerebral ischemia,[27] are increased after head injury and may alter membrane permeability through activation of ligand-gated channels. Similarly, following injury, direct mechanical stimulation can cause ionic fluxes and neuron firing. This ionic destabilization places enormous energy demands on the cells to activate pumping mechanisms to restore the ionic balance in the first few hours after trauma.[20] Microdialysis studies in head-injured patients demonstrate elevated glutamate levels during episodes of jugular oxygen desaturation.[41] Whether the failure of $\mathrm{AVDO}_{2}$ to improve after treatment reflects a continued demand for oxygen to restore membrane stability affected by sustained excitotoxicity or mechanical disruption is not clear from our study. However, the failure of $\mathrm{AVDO}_{2}$ to improve after treatment does define a subgroup of patients who, after treatment, can progress to cerebral infarction despite adequate CPP.

\section{Arteriovenous Oxygen Difference and Outcome}

The results in this series demonstrate that a limited improvement in elevated $\mathrm{AVDO}_{2}$ following craniotomy or mannitol administration is associated with an unfavorable outcome and supports a role for $\mathrm{AVDO}_{2}$ monitoring as a predictive tool in head injury. By contrast, posttreatment ICP and CPP in this group of severely head injured patients were not reliable outcome predictors. Several investigators using continuous jugular oxygen monitors have observed a significant association between episodes of jugular oxygen desaturation and poor outcome following head injury.[10,11,40,41,46] For example, Robertson, et al.,[41] observed a $21 \%$ mortality rate in patients with no desaturation, $37 \%$ after a single episode, and $69 \%$ after multiple episodes. Poor outcome may also be associated with a reduced $\mathrm{AVDO}_{2},[21,40]$ because cerebral metabolism is significantly depressed once cerebral infarction has occurred.

Outcome after head injury depends on many variables; although not conclusive, the observations in this report lead us to suggest that posttreatment levels of $\mathrm{AVDO}_{2}$ may provide reliable and, perhaps, independent outcome prediction. In other studies evaluating continuous jugular oxygen saturation after head injury, multivariate analysis has indicated that after adjustment for outcome determinants such as age, ICP, and GCS score, the number of desaturations continues to demonstrate a significant association 
with outcome: one episode of desaturation doubled the risk of a poor outcome, whereas multiple desaturations were associated with a 14-fold increase in the risk of poor outcome.[18] Whether the predictive information provided by $\mathrm{AVDO}_{2}$ monitoring is a useful management tool is not addressed in this study. The ability to predict outcome, however, is important because when outcome can be accurately predicted, management can be directed at potentially avoidable deleterious factors. In addition, physiological categorization, based on $\mathrm{AVDO}_{2}$ values, of patients at risk for delayed cerebral infarction before CT evidence for ischemia is observed, may help distinguish different causes of intracranial hypertension or cerebral ischemia early in the patient's clinical course when specific targeted therapies are ideally started.

\section{Applications for Jugular Oxygen Monitoring}

The observations described in this report demonstrate that repeated $\mathrm{AVDO}_{2}$ measurements are more reliable than a single pretreatment measurement. In addition, posttreatment $\mathrm{AVDO}_{2}$ values are best interpreted by comparing them with pretreatment values. Intermittent CBF measurements may similarly miss episodes of reversible ischemia.[43] Therefore, continuous $\mathrm{SjVO}_{2}$ monitors, which use oximetric techniques, have been developed. The relationship between $\mathrm{AVDO}_{2}$ and $\mathrm{SjVO}_{2}$ is reciprocal. Although interpretation of $\mathrm{SjVO}_{2}$ is based on several assumptions, a good correlation between $\mathrm{SjVO}_{2}$ measured fiberoptically and via catheter has been observed.[46] Unfortunately, jugular saturation monitors require frequent recalibration and a high percentage of readings are erroneous because of catheter movement, displacement, intimal impaction, or clot formation.[14,46] Despite these limitations, jugular saturation monitoring can help guide therapy, optimize CPP, and measure the effects of therapeutic interventions, such as ventilation or mannitol administration, to ensure adequate $\mathrm{CBF}$ to meet metabolic demands.[8,10,11,35,49] Jugular saturation monitors may also detect transient episodes of cerebral hypoxia from potentially preventable systemic causes such as hypotension, hypoxia, fever, or seizures.[11,18,40]

The identification of inadequate cerebral oxygenation is important in the management of cases of head injury. The validity of using CPP as a measure of cerebral oxygenation becomes limited when autoregulatory mechanisms are disturbed and it also leads one to ignore other potential causes of cerebral ischemia after head injury. Results obtained in cerebral blood flow studies are disappointing in identifying which patient is at risk for ischemia because reduced, normal, and increased flow can be associated with a poor outcome.[5,28,30,34,36-40] These discrepancies may result, in part, from methodological differences. However, quantification of $\mathrm{CBF}$ alone cannot define the relationship between oxygen supply and consumption because the adequacy of oxygenation is also determined by variables such as autoregulation, $\mathrm{CO}_{2}$ reactivity, and coupling of $\mathrm{CBF}$ and cerebral metabolism that are disturbed in a significant number of head-injured patients.[2,3,9,14,26,34,36] Furthermore, confounding variables such as vasospasm, anemia, hypoxia, and seizures may reduce the oxygen carrying capacity. A measure of the balance between cerebral oxygen delivery and consumption, such as $\mathrm{AVDO}_{2}$, may therefore be useful and, when combined with multimodality monitoring, may provide a reasonable means to identify patients in which secondary ischemic damage can be ameliorated by therapeutic intervention directed at its pathophysiological mechanism.

\section{References}


1. Baker AJ, Moulton RJ, MacMillan VH, et al: Excitatory amino acids in cerebrospinal fluid following traumatic brain injury in humans. J Neurosurg 79:369-372, 1993

2. Bouma GJ, Muizelaar JP: Relationship between cardiac output and cerebral blood flow in patients with intact and with impaired autoregulation. J Neurosurg 73:368-374, 1990

3. Bouma GJ, Muizelaar JP, Bandoh K, et al: Blood pressure and intracranial pressure-volume dynamics in severe head injury: relationship with cerebral blood flow. J Neurosurg 77:15-19, 1992

4. Bouma GJ, Muizelaar JP, Choi SC, et al: Cerebral circulation and metabolism after severe traumatic brain injury: the elusive role of ischemia. J Neurosurg 75:685-693, 1991

5. Bruce DA, Langfitt TW, Miller JD, et al: Regional cerebral blood flow, intracranial pressure, and brain metabolism in comatose patients. J Neurosurg 38:131-144, 1973

6. Bullock R, Butcher SP, Chen MH, et al: Correlation of the extracellular glutamate concentration with extent of blood flow reduction after subdural hematoma in the rat. J Neurosurg 74:794-802, 1991

7. Chan KH, Dearden NM, Miller JD, et al: Multimodality monitoring as a guide to treatment of intracranial hypertenion after severe brain injury. Neurosurgery 32:547-553, 1993

8. Chan KH, Miller JD, Dearden NM, et al: The effect of changes in cerebral perfusion pressure upon middle cerebral artery blood flow velocity and jugular bulb venous oxygen saturation after severe brain injury. J Neurosurg 77:55-61, 1992

9. Cold GE, Jensen T: Cerebral autoregulation in unconscious patient with brain injury. Acta Anaesthesiol Scand 22:270-280, 1978

10. Cruz J: An additional therapeutic effect of adequate hyperventilation in severe acute brain trauma: normalization of cerebral glucose uptake. J Neurosurg 82:379-385, 1995

11. Cruz J, Gennarelli TA, Alves WM: Continuous monitoring of cerebral hemodynamic reserve in acute brain injury: relationship to changes in brain swelling. J Trauma 32:629-635, 1992

12. Dearden NM: Jugular bulb venous oxygen saturation in the management of severe head injury. Curr Opin Anaesthesiol 4:279-286, 1991

13. Faden AI, Demediuk P, Panter SS, et al: The role of excitatory amino acids and NMDA receptors in traumatic brain injury. Science 244:798-800, 1989

14. Fortune JB, Feustel PJ, Weigle CG, et al: Continuous measurement of jugular venous oxygen saturation in response to transient elevations of blood pressure in head-injured patients. J Neurosurg 80:461-468, 1994

15. Gibbs F, Lennox W, Gibbs E: Bilateral internal jugular blood. Comparison of AV differences, oxygen dextrose ratios and respiratory quotients. Am J Psychiatry 102:184-190, 1945

16. Gibbs F, Lennox W, Gibbs E: Cerebral blood flow preceding and accompanying epileptic seizures in man. Arch Neurol Psychiatry 32:257-272, 1934

17. Goetting MG, Preston G: Jugular bulb catheterization does not increase intracranial pressure. Intensive Care Med 17:195-198, 1991 
18. Gopinath SP, Robertson CS, Contant CF, et al: Jugular venous desaturation and outcome after head injury. J Neurol Neurosurg Psychiatry 57:717-723, 1994

19. Graham DI, Adams JH, Doyle D: Ischaemic brain damage in fatal non-missile head injuries. J Neurol Sci 39:213-234, 1978

20. Hovda DA, Becker DP, Katayama Y: Secondary injury and acidosis. J Neurotrauma 9 (Suppl 1):S47-S60, 1992

21. Jaggi JL, Obrist WD, Gennarelli TA, et al: Relationship of early cerebral blood flow and metabolism to outcome in acute head injury. J Neurosurg 72:176-182, 1990

22. Jakobsen M, Enevoldsen E: Retrograde catheterization of the right internal jugular vein for serial measurements of cerebral venous oxygen content. J Cereb Blood Flow Metab 9:717-720, 1989

23. Jennett B, Bond M: Assessment of outcome after severe brain damage. A practical scale. Lancet 1:480-484, 1975

24. Kotapka MJ, Graham DI, Adams JH, et al: Hippocampal pathology in fatal head injury without high intracranial pressure. J Neurotrauma 11:317-324, 1994

25. Kuroda Y, Bullock R: Local cerebral blood flow mapping before and after removal of acute subdural hematoma in the rat. Neurosurgery 30:687-691, 1992

26. Lewelt W, Jenkins LW, Miller JD: The effects of experimental fluid-percussion injury of the brain on cerebrovascular reactivity to hypoxia and hypercapnia. J Neurosurg 56:332-338, 1982

27. Lipton SA, Rosenberg PA: Excitatory amino acids as a final common pathway for neurologic disorders. N Engl J Med 330:613-622, 1994

28. Marion DW, Darby J, Yonas H: Acute regional cerebral blood flow changes caused by severe head injuries. J Neurosurg 74:407-414, 1991

29. Martin NA, Doberstein C, Alexander M, et al: Posttraumatic cerebral arterial spasm. J Neurotrauma 12:879-901, 1995

30. Mendelow AD, Teasdale GM, Russell T, et al: Effect of mannitol on cerebral blood flow and cerebral perfusion pressure in human head injury. J Neurosurg 63:43-48, 1985

31. Miller JD: Head injury and brain ischaemia--implications for therapy. Br J Anesth 57:120-130, 1985

32. Miller JD, Bullock R, Graham DI, et al: Ischemic brain damage in a model of acute subdural hematoma. Neurosurgery 27:433-439, 1990

33. Moulton RJ, Shedden PM, Tucker WS, et al: Somatosensory evoked potential monitoring following severe closed head injury. Clin Invest Med 17:187-195, 1994

34. Muizelaar JP, Ward JD, Marmarou A, et al: Cerebral blood flow and metabolism in severely head-injured children. Part 2: Autoregulation. J Neurosurg 71:72-76, 1989

35. Nordström CH, Messeter K, Sundbärg G, et al: Cerebral blood flow, vasoreactivity, and oxygen consumption during barbiturate therapy in severe traumatic brain lesions. J Neurosurg 68:424-431, 1988 
36. Obrist WD, Gennarelli TA, Segawa H, et al: Relation of cerebral blood flow to neurologic status and outcome in head-injured patients. J Neurosurg 51:292-300, 1979

37. Obrist WD, Langfitt TW, Jaggi JL, et al: Cerebral blood flow and metabolism in comatose patients with acute head injury. Relationship to intracranial hypertension. J Neurosurg 61:241-253, 1984

38. Overgaard J, Mosdal C, Tweed WA: Cerebral circulation after head injury. Part 3: Does reduced regional cerebral blood flow determine recovery of brain function after blunt head injury? J Neurosurg 55:63-74, 1981

39. Overgaard J, Tweed WA: Cerebral circulation after head injury. Part 1: Cerebral blood flow and its regulation after closed head injury with emphasis on clinical correlations. J Neurosurg 41:531-541, 1974

40. Robertson CS, Contant CF, Gokaslan ZL, et al: Cerebral blood flow, arteriovenous oxygen difference, and outcome in head injured patients. J Neurol Neurosurg Psychiatry 55:594-603, 1992

41. Robertson CS, Gopinath SP, Goodman JC, et al: $\mathrm{SjvO}_{2}$ monitoring in head-injured patients. J Neurotrauma 12:891-896, 1995

42. Robertson CS, Grossman RG, Goodman JC, et al: The predictive value of cerebral anaerobic metabolism with cerebral infarction after head injury. J Neurosurg 67:361-368, 1987

43. Robertson CS, Narayan RK, Gokaslan ZL, et al: Cerebral arteriovenous difference as an estimate of cerebral blood flow in comatose patients. J Neurosurg 70:222-230, 1989

44. Rosner MJ, Rosner SD, Johnson AH: Cerebral perfusion pressure: management protocol and clinical results. J Neurosurg 83:949-962, 1995

45. Schröder ML, Muizelaar JP, Bullock MR, et al: Focal ischemia due to traumatic contusions documented by stable xenon-CT and ultrastructural studies. J Neurosurg 82:966-971, 1995

46. Sheinberg M, Kanter MJ, Robertson CS, et al: Continuous monitoring of jugular venous oxygen saturation in head-injured patients. J Neurosurg 76:212-217, 1992

47. Shenkin H, Harmel M, Kety S: Dynamic anatomy of the cerebral circulation. Arch Neurol Psychiatry 60:240-252, 1948

48. Stocchetti N, Paparella A, Bridelli F, et al: Cerebral venous oxygen saturation studied with bilateral samples in the internal jugular veins. Neurosurgery 34:38-44, 1994

49. Sutton LN, McLaughlin AC, Dante S, et al: Cerebral venous oxygen content as a measure of brain energy metabolism with increased intracranial pressure and hyperventilation. J Neurosurg 73:927-932, 1990

50. Sutton LN, McLaughlin AC, Kemp W: Effects of increased ICP on brain phosphocreatine and lactate determined by simultaneous ${ }^{1} \mathrm{H}$ and ${ }^{31} \mathrm{P}$ NMP spectroscopy. J Neurosurg 67:381-386, 1987

51. Teasdale G, Jennett B: Assessment of coma and impaired consciousness. A practical scale. Lancet 2:81-84, 1974 
Manuscript received July 30, 1996.

Accepted in final form February 25, 1997.

Address for Dr. Le Roux: New York University Medical Center, New York, New York.

Address reprint requests to: H. Richard Winn, M.D., Department of Neurosurgery, University of

Washington, Seattle, Washington 98195. 